\title{
PULSE WAVE PROPAGATING IN COPLANAR WAVEGUIDES (CPWS) ON LTCC SUBSTRATES
}

W. Y. Yin, B. Guo, and X. T. Dong

Temasek Laboratories

National University of Singapore

Singapore 119260

Received 17 September 2002

ABSTRACT: The propagation of pulse waves in coplanar waveguides $(C P W s)$ is investigated, and these CPWs are assumed to be fabricated on a single-layer low-temperature co-fired ceramic (LTCC) substrate. The input pulse wave can be a Gaussian pulse or a sinusoidally modulated Gaussian pulse. Based on the standard Galerkin's method in the spectral domain, combined with fast Fourier transform (FFT), the pulse waveform and delay in CPWs are demonstrated and compared for

, No. 1, April 52003 
a second plate, oriented orthogonally to the primary planar element, thus producing a crossed planar monopole (CPM), which is simpler to produce and has lower cost than a conical monopole. In this paper, further measurements have been made on this element.

\section{ANTENNA GEOMETRY AND IMPEDANCE PROPERTIES}

The simple planar monopole consists of a planar element that is fed using an SMA feedprobe. The planar elements were constructed using a 0.2-mm-thick copper sheet and the grour.dplane dimensions were $100 \times 100 \mathrm{~mm}$. This simple square planar monopole of dimension $L=W=18 \mathrm{~mm}$, with a feedgap of 2 $\mathrm{mm}$, has a return loss (RL) greater than $10 \mathrm{~dB}$ from 2.95 to 6.9 $\mathrm{GHz}$. The upper-edge frequency $(10-\mathrm{dB} \mathrm{RL})$ is extended to beyond $10.5 \mathrm{GHz}$ by using a $20^{\circ}$ bevel. The lower-edge frequency is not significantly changed by the bevel. The geometry for the simple planar monopole with bevel (SPMB) is illustrated in Figure 1(a). The crossed planar monopole (CPM) comprises a second planar element added and oriented orthogonally to the original element, as illustrated in Figure 1(b). The width of each element was reduced to $W=9 \mathrm{~mm}$, which maintains the same surface area as the simple planar monopole. The return loss plots are shown in Figure 2 for these antennas. The lower edge frequencies for the SPMB and CPM are 3.0 and $3.1 \mathrm{GHz}$, respectively. The upperedge frequency for the CPM is $9.55 \mathrm{GHz}$, but still presents a $9-\mathrm{dB}$ return loss at $10.5 \mathrm{GHz}$.

\section{STABILITY OF RADIATION PATTERN}

One of the challenges in wideband planar antennas is maintaining an omnidirectional pattern as the frequency increases, which is readily observed from $H$-plane plots. Radiation patterns have been measured at $2.4,4.8,6.8$, and $9 \mathrm{GHz}$ for the bevelled planar monopole and the crossed planar monopole. The $H$-plane patterns $E_{\theta}(\phi, \theta=90)$ are illustrated in Figure 3. At $2.4 \mathrm{GHz}$, both patterns were purely omnidirectional (they are not shown for the sake of brevity). It can be seen that the simple planar monopole with bevel exhibits distortion in the pattern, particularly at higher frequencies with broad nulls up to a depth of $9 \mathrm{~dB}$ at $9 \mathrm{GHz}$. In contrast, the patterns for the crossed planar monopole remain very stable with frequency with a maximum deviation of $2.8 \mathrm{~dB}$ from a purely omnidirectional pattern at $9 \mathrm{GHz}$. The patterns are normalised to maximum gain, which is $4.3 \mathrm{dBi}$ at the lower frequencies and increases with frequency to about $6.0 \mathrm{dBi}$.

\section{CONCLUSION}

The addition of a second planar element orthogonal to the planar monopole improves the radiation pattern stability without degrading the ultra-wideband impedance characteristics.

\section{REFERENCES}

I. T. Tsukiji, Y. Kumon, and M. Yamasaki, Double-folded monopole antenna using parallel line or coaxial line, IEEE Proc Microwave Antennas Propagat 149 (2002), 17-22.

2. Z.N. Chen, Note on impedance characteristics of L-shaped wire monopole antennas, Microwave Optical Technol Lett 26 (2000), 22-23.

3. M.J. Ammann, Downsizing inverted-F antennas for $915-\mathrm{MHz}$ ISM applications, Microwave Optical Technol Lett 31 (2001), 270-271.

4. P.A. Agrawall, G. Kumar, and K. Ray, Wideband planar monopole antennas, IEEE Trans Antennas Propagat AP-46 (1998), 294-295.

5. S. Honda, M. Ito, H. Seki, and Y. Jinbo, A disk monopole antenna with 1:8 impedance bandwidth and omnidirectional radiation pattern, Proc ISAP, Sapporo, Japan, (1992), pp. 1145-1148.

6. M.J. Ammann and Z.N. Chen, Wideband monopole antennas for multiband wireless systems, IEEE Antennas Propagat Mag 45 (2003), 146150. 
7. M.J. Ammann and Z.N. Chen, A wideband shorted planar monopole with bevel, IEEE Trans Antennas Propagat AP-5I (2003), 901-903.

8. J.A. Evans and M.J. Ammann, Planar monopole design considerations based on TLM estimation of current density, Microwave Optical Technol Lett 36 (2003), 40-42.

9. M.J. Ammann, Improved pattern stability for monopole antennas with ultrawideband impedance characteristics, IEEE Int Antennas Propagat Symp Dig, Columbus, OH, 2003, pp. 818-821.

(1) 2004 Wiley Periodicals, Inc. 